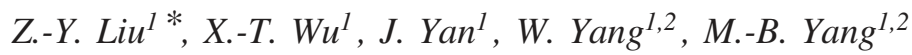

${ }^{1}$ College of Polymer Science and Engineering, Sichuan University, Chengdu, Sichuan, PRC

${ }^{2}$ State Key Laboratory of Polymer Materials Engineering, Sichuan University, Chengdu, Sichuan, PRC

\title{
Effect of Annealing Temperature on PP Microporous Membranes Obtained by a Melt-Extrusion-Stretching Method
}

Isotactic polypropylene (iPP) precursor film with highly oriented lamellar structure was produced through a melt extrusionannealing-uniaxial stretching (MAUS) process. The precursor films were annealed at various temperatures and the structure evolution of precursor films during various annealing temperatures and the pore formation of the annealed film during stretching were investigated. During annealing, recrystallized lamellar structure was formed to obtain "core-shell sandwich" structure. The thickness of newly formed lamellae increased with annealing temperature, which improved the ability of slipping resistance of the original lamellar structure during stretching. As the annealing temperature of precursor film increased, the micropore shape and diameter of the final membranes became more uniform. The porosity of the microporous membranes increased with increasing annealing temperature.

\section{Introduction}

Polymer-based microporous membranes are an important type of new functional materials which are widely used in water purification, battery separator (Arora and Zhang, 2004), biomedical separation (Cheng et al., 2018; Himma et al., 2016) and so on. After the first patent from Celanese in the $1970 \mathrm{~s}$ for the production of single-layer polypropylene microporous membranes by a melt extrusion-annealing-uniaxial stretching (MAUS) process (Bierenbaum et al., 1974), dry-stretching technique based on the stretching of polymer film or sheet containing row-nucleated lamellar structure has generally been industrialized and researched (Tabatabaei et al., 2008; Saffar et al., 2014; Li et al., 2018; Xiong et al., 2018). The effects of molecular weight and molecular weight distribution of resin, air cooling, chill roll temperature, and draw ratio on the row-nucleated lamellar structure and orientation of precursor film developed in PP cast films, and consequently on the micropore structure and mechanical properties of the resulting membranes after stretching stage, have been investigated (Tabatabaei et al., 2008; 2009;

\footnotetext{
* Mail address: Zhengying Liu, College of Polymer Science and Engineering, Sichuan University, Chengdu 610065, Sichuan, PRC

E-mail: Liuzhying@scu.edu.com
}

$\mathrm{Xu}$ et al., 2018; Xu et al., 2015). Annealing the precursor film at temperatures near the melting point of the resin is the necessary and final stage of MAUS method for preparing polypropylene microporous films, where the orientation and the arrangement of row-nucleated lamella would be changed to improve the formation and uniformity of the micropores (Saffar et al. 2014; Lin et al., 2018; Wang et al., 2015).

Annealing time and annealing temperature are two important controlling factors. Mostly, 140 to $145^{\circ} \mathrm{C}$ were selected by researchers to study the effect of annealing temperature on the microstructure of precursor film (Tabatabaei et al., 2008; 2009). During annealing the mobility of the chains in the interface of the crystal-amorphous regions and amorphous regions increases significantly. Incorporation of the segments of loose tie chains into the crystallites is probably induced, which results in an increase of lamellae thickness and an increase in the overall degree of crystallinity. Sadeghi et al. (2007) indicated that an efficient annealing time was $10 \mathrm{~min}$ at $140^{\circ} \mathrm{C}$; beyond $10 \mathrm{~min}$ the lamellar structure parameters (the thickness, orientation and the perfection of the lamellae) remained constant. In our previous report (Ding et al., 2013), the influence of annealing time at $135^{\circ} \mathrm{C}$ on the orientation state, micropore formation and permeability was investigated. The results suggested that the orientation in the crystalline regions $\left(f_{c}\right)$ and amorphous regions $\left(f_{a m}\right)$ and crystallinity $\left(\mathrm{X}_{\mathrm{c}}\right)$ increased sharply with the annealing time mainly before $200 \mathrm{~s}$, especially before $40 \mathrm{~s}$. As the annealing time increased within $200 \mathrm{~s}$, the $\mathrm{f}_{\mathrm{c}}$ and $\mathrm{f}_{\mathrm{am}}$ of precursor film increased, which is in favor of the increase of micropores number and pore size of the final membranes.

In the MAUS process, the annealing temperature is thought to be the most effective parameter in annealing to affect the lamellar structure and as well as $f_{c}$ and/or $f_{a m}$. Sadeghi et al. (2007) concluded that the annealing temperature highly improved the crystal phase orientation but had a much weaker effect on the amorphous phase. Rosova et al. (1996) suggested that the chain segments in the amorphous regions were drawn into the crystallites during annealing. The length of the polymer chains folds in the lamellae increased with the increase of annealing temperature, yielding a narrower length distribution of tie chains and larger number of stretched tie chains. Lee et al. (2006) proposed that the lamellar thickness tended to be larger and its distribution became broader as the annealing 
temperature increases. Lei et al. investigated the influence of annealing temperature on the row-nucleated lamellae and connecting bridge arrangement of PP membrane in the temperature range from 105 to $145^{\circ} \mathrm{C}$ (Cai et al., 2015). They found that some weak secondary crystals were induced by annealing and the content of secondary crystals increased with the increase of annealing temperature. The secondary crystals induced by annealing converted to initial connecting bridges, which lead to the best connecting bridge arrangement for the membrane. Guo et al. (2015) reported that with the increase of annealing temperature the crystallinity and crystalline orientation of precursor films increased, accompanied by the decrease of the entanglements in the amorphous phase.

The research results have not summarized the law of the annealing-structure-property relationship of PP microporous membranes. From our previous studies of the optimum conditions (Liu et al., 2011) for preparing microporous membranes and the effect of the content of high molecular weight fractions on the porous structure and distribution (Ding et al. 2012), we have further studied the influence of annealing temperature on orientation of the lamellae and crystalline structure of the precursor films and, in turn, their effect on the membranes performance during the microporous membranes preparation. Then, a "coreshell sandwich" model was proposed to describe the annealingstructure-property relationship of PP microporous membranes.

\section{Experimental}

\subsection{Material and Membrane Preparation}

A commercially available isotactic polypropylene (iPP, PP5341E1) with melt flow rate of $0.5 \mathrm{~g} / 10 \mathrm{~min}\left(230^{\circ} \mathrm{C} /\right.$ $2.16 \mathrm{~kg})$ and molecular mass $\mathrm{M}_{\mathrm{w}}=680 \mathrm{~kg} / \mathrm{mol}\left(\mathrm{M}_{\mathrm{w}} / \mathrm{M}_{\mathrm{n}}=3.3\right)$ was purchased from ExxonMobil (Irving, Texas, USA) and used as received. The molecular parameters were measured by gel permeation chromatography (GPC, PL-GPC200) at $150^{\circ} \mathrm{C}$, with 1,2,4-trichlorobenzene as a solvent.

The precursor films were prepared by cast film processing through a single screw extruder (SJ-20BX25, Shanghai Kechuang Rubber Plastic Machinery Set, Shanghai, PRC, $\mathrm{D}=30 \mathrm{~mm}, \mathrm{~L} / \mathrm{D}=34$, where $\mathrm{D}$ is the diameter of the screw and $\mathrm{L}$ is the length of the screw) equipped with a slit die (1.8 0.1 $\mathrm{mm}$ thick and $100 \mathrm{~mm}$ width), three roller traction machine and a drying oven. The temperatures of the three sections of the single-screw extruder and the die were $190^{\circ} \mathrm{C}$, $210^{\circ} \mathrm{C}, 230^{\circ} \mathrm{C}$ and $225^{\circ} \mathrm{C}$, respectively, and the screw speed of the extruder was $40 \mathrm{~min}^{-1}$. To improve cooling, two fans were installed to supply air to the film surface right at the exit of the die. The gas flow rate of each fan was $3 \mathrm{l} / \mathrm{s}$. Precursor films with the melt traction ratio of $90\left(\mathrm{DR}=\mathrm{V}_{\text {draw }} / \mathrm{V}_{\text {extrude }}=\right.$ 60 , where $V_{\text {draw }}$ is the three-roll tractor drawing line speed and $\mathrm{V}_{\text {extrude }}$ is the melt extrusion velocity) were obtained.

Following extrusion and drawing the precursor films were cut into rectangle-shape samples of $0.5 \times 2 \mathrm{~mm}^{2}$ and then the samples were annealed thermostatically in an oven at various temperatures $\left(80,90,100,120,130\right.$ and $\left.140^{\circ} \mathrm{C}\right)$ for $30 \mathrm{~min}$ for the subsequent stretching process.

A universal testing machine (AGS-J, Shimadzu, Kyoto, Japan) equipped with a temperature control chamber was used for stretching the annealed films. There were two steps of the stretching process: first of all, the annealed samples were cold stretched $40 \%$ at $25^{\circ} \mathrm{C}$ with a stretching speed of $200 \mathrm{~mm} /$ min; secondly, the samples were stretched again by $40 \%$ with a stretching speed of $20 \mathrm{~mm} / \mathrm{min}$ after the temperature was elevated to $120^{\circ} \mathrm{C}$. Cold stretching led to lamellar separation and pore creation, while the following hot stretching led to pore elongation. Finally, the microporous membranes were obtained by heat setting with clamping state at $120^{\circ} \mathrm{C}$ for $20 \mathrm{~min}$ after the hot stretching.

\subsection{Characterization}

The infrared spectra were recorded on a Nicolet 6700 FTIR instrument (Thermo Electron Corp., Madison, USA) in the range $400-4000^{-1}$ in the transmission mode, with a frequency resolution $4 \mathrm{~cm}^{-1}$ and accumulation of 16 scans. If the films are oriented, the absorption of plane-polarized radiation by a vibration in two orthogonal directions, specifically parallel and perpendicular to a reference axis (machine direction), should be different (as shown in Fig. 1A). The dichroic ratio (D) is defined as $\mathrm{D}=\mathrm{A}_{/ /} / \mathrm{A}_{\perp}$, where $\mathrm{A}_{/ /}$is the absorption parallel and $\mathrm{A}_{\perp}$ is the absorption perpendicular to the specific reference axis (Tabatabaei et al., 2007; 2008; 2009). The Herman orientation function of this vibration is obtained according to $f=(D-1) /(D+2)$. For polypropylene, absorption at the wavenumber of $998 \mathrm{~cm}^{-1}$ is attributed to the crystalline phase (c-axis) while that at $972 \mathrm{~cm}^{-1}$ is due to the contribution of both crystalline and amorphous phases (Sadeghi et al., 2007). The absorption peak with wavenumber $998 \mathrm{~cm}^{-1}$ was used to calculate $\mathrm{f}_{\mathrm{c}}$, along the MD, of the samples annealed at various temperatures.

The thermal properties of the specimens annealed at different temperatures for 30 min were analyzed using a differential scanning calorimeter (DSC TA Q20, Cranston, Rhode Island, USA) in a nitrogen gas atmosphere. Samples were heated from 50 to $220^{\circ} \mathrm{C}$ at a heating rate of $10^{\circ} \mathrm{C} / \mathrm{min}$.

A field emission scanning electron microscope (Inspect $\mathrm{F}$, FEI Company, Cambridge, USA) was employed to examine the surface morphologies of the stretched samples. The accelerating voltage was $10 \mathrm{kV}$ and the samples were gold coated before observations.

The liquid absorption method (ASTMD-2873) was used to detect the porosity $(\varepsilon)$ of the microporous membranes based on three steps:

1. weighing the microporous membranes ( $\left.\mathrm{m}_{\text {microporous membranes }}\right)$;

2. dipping the microporous membranes in hexadecane for $1 \mathrm{~h}$;

3. weighing the sample after wiping the surface by filter paper

$\left(\mathrm{m}_{\text {microporous membranes }}+\mathrm{m}_{\text {hexadecane }}\right)$.

The porosities $(\varepsilon)$ of the microporous membranes were obtained according to:

$$
\begin{aligned}
\mathrm{E}= & \left(\mathrm{m}_{\text {hexadecane }} / \rho_{\text {hexadecane }}\right) /\left(\mathrm{m}_{\text {microporous membranes }} / \rho_{\text {polymer }}\right. \\
& +\mathrm{m}_{\text {hexadecane }} / \rho_{\text {hexadecane }},
\end{aligned}
$$

where $\rho_{\text {hexadecane }}$ and $\rho_{\text {polymer }}$ are the densities of hexadecane and polymer, respectively.

A Shimadzu AGS-J universal testing machine was used for the tension test. Strain rates of $30 \mathrm{~mm} / \mathrm{min}$ were utilized during tensile tests. The samples were tested at $25^{\circ} \mathrm{C}$. 


\section{Results and Discussion}

\subsection{Effect of Annealing Temperature on the Lamellar Structure of the Precursor Films}

Figure 1 shows the changes of the orientation parameter in the crystalline regions $\left(\mathrm{f}_{\mathrm{c}}\right)$ of the precursor films annealed at various temperatures ranging from 80 to $140{ }^{\circ} \mathrm{C}$. The inset image exhibits an enlarged view of the first $200 \mathrm{~s}$ of the curves. The orientation of the samples annealed at the various temperatures increased with the increasing annealing time up to ca. $1000 \mathrm{~s}$. Especially, during the annealing time of $20 \mathrm{~s}$ to $200 \mathrm{~s}$, the $\mathrm{f}_{\mathrm{c}}$ of each sample increased with increasing annealing time and le- veled off beyond $1000 \mathrm{~s}$. It is notable that the growth rate and the stable values of $f_{c}$ grew with the increase of the annealing temperature, especially for the samples annealed at $130{ }^{\circ} \mathrm{C}$ and $140{ }^{\circ} \mathrm{C}$. Obviously, the annealing temperature had a greater positive effect on the final $\mathrm{f}_{\mathrm{c}}$ of the annealed precursor film than the annealing time. When the annealing temperature increased, larger movement units in the iPP molecular chains would be triggered to obtain more perfect lamellar structure which contributed to the increase of orientation of the lamellae.

To detect the changes of the crystalline structure, the annealed films with the various annealing temperatures were investigated by DSC and the results were shown in Fig. 2. The inset is a vertical enlargement of the curves inside the dotted box.
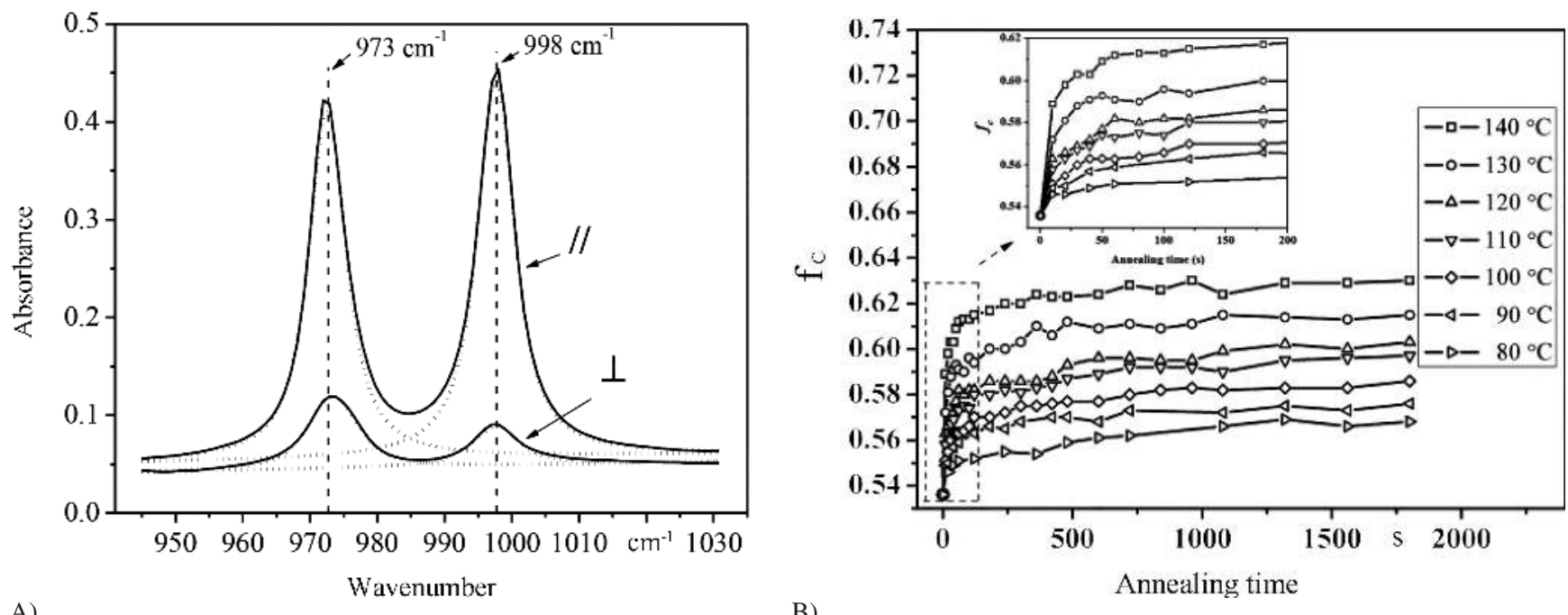

Fig. 1. The decomposition of the band between 945 to $1030 \mathrm{~cm}^{-1}$ of $i P P(A)$ and the changes of the orientation parameters $\left(f_{c}\right)$ of the precursor films annealed at various temperatures $(B)$

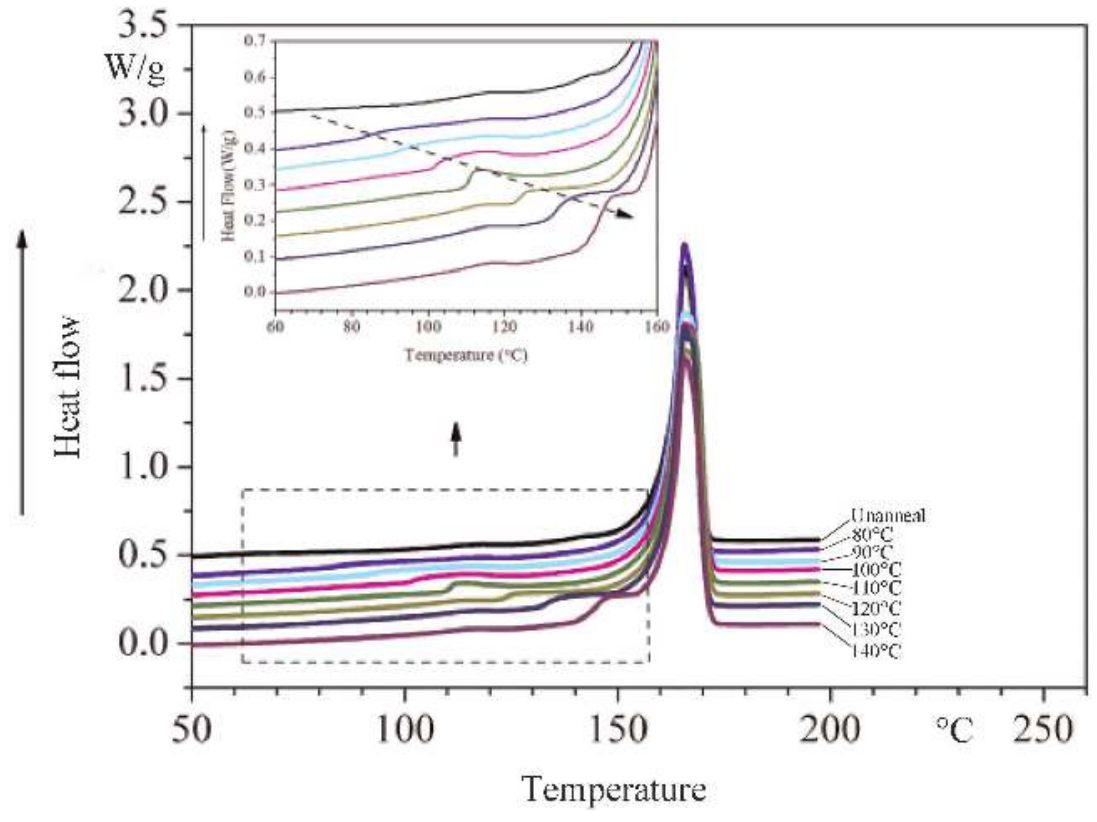

Intern. Polymer Processing XXXIV (2019) 4
Fig. 2. The DSC curves of the unannealed film and the films annealed at different annealing temperatures for $30 \mathrm{~min}$ 
From Fig. 2, the positions of the main melting peak (Tm, about $165^{\circ} \mathrm{C}$ ) of samples did not change with the increase of annealing temperature. Significantly, a slight shoulder appeared at lower temperature $\left(\mathrm{Tm}^{\prime}\right)$ for the annealed films, attributed to the formation of imperfect lamellae during annealing. The newly formed lamellae were thought to come from the arrangement of tie chains in the amorphous phase. With increasing annealing temperature, the shoulder peak at lower temperature became prominent, meaning the $\mathrm{Tm}^{\prime}$ of newly formed lamellae increased as the annealing temperature increased.

The lamellar thickness (L) can be obtained from DSC data using the Thomson-Gibbs equation (Valles-Lluch et al.,2003; Włochowicz and Eder, 1984):

$\mathrm{L}=\frac{2 \sigma_{\mathrm{e}}}{\Delta \mathrm{H}_{\mathrm{m}}^{0}} \frac{\mathrm{T}_{\mathrm{m}}^{0}}{\mathrm{~T}_{\mathrm{m}}^{0}-\mathrm{T}_{\mathrm{m}}} \times 10^{9}$.

For iPP the free fold surface energy $\sigma_{\mathrm{e}}$ and the equilibrium melting point of the $100 \%$ crystalline material $\mathrm{T}_{\mathrm{m}}{ }^{0}$ are assumed to be $0.07 \mathrm{~J} / \mathrm{m}^{2}$ and $460.65 \mathrm{~K}$, respectively (Clark et al., 1984). The heat of fusion per unit volume $\Delta \mathrm{H}_{\mathrm{m}}{ }^{0}$ was calculated from the heat of fusion of an ideally crystalline sample $\left(\Delta \mathrm{H}_{\mathrm{m}}{ }^{0}=207 \mathrm{~J} / \mathrm{g}\right)($ Clark et al., 1984) on the basis of the density of perfectly crystalline iPP, $\rho_{\mathrm{c}}=936 \mathrm{~kg} / \mathrm{m}^{3}$ and $\mathrm{Tm}$ (or Tm') was the melting temperature as derived from the DSC experiments. The thickness of the original lamellae and the newly formed lamellae of the annealed films at different temperatures, based on Eq. 2 using the Tm and Tm' from Fig. 2, respectively, are listed in Table 1.

The total crystallinities (Xc) of iPP precursor films without and with annealing are calculated using the relationship:

Crystallinity $\left.=\left(\Delta \mathrm{H}_{\mathrm{m}} / \Delta \mathrm{H}_{\mathrm{m}}^{0}\right) \times 100 \%\right)$,

where $\Delta \mathrm{H}_{\mathrm{m}}$ is the observed heat of fusion and $\Delta \mathrm{H}_{\mathrm{m}}{ }^{0}$ is $207 \mathrm{~J} / \mathrm{g}$. The Xc results were also listed in Table 1.

From Table 1, the original crystalline lamellae were not thickened and broadened after annealing. Also, with the increase of the annealing temperature, even annealing at $140^{\circ} \mathrm{C}$, the thickness of the original lamellae and distribution of lamellae thickness remained the same. So, the increase of overall crystallinity of annealed film was assigned to the formation of imperfect lamellae during annealing. The thickness and the perfection of the newly formed lamellae continuously increased with the increase of the annealing temperature (Ta- ble 1), which also induced a continuous increase of the overall crystallinity of the samples. At the annealing temperature (80 to $140^{\circ} \mathrm{C}$ ), molecules in amorphous phase had enough energy to rearrange and fold, leading to the growth of imperfect lamellae. When the annealing temperature was higher, the movement of longer units of molecular chains was triggered. And enhancing movement units would result in the increasing and the thickening of newly formed lamellae.

\subsection{Effect of Annealing Temperature on the Tensile Deformation Behavior of the Precursor Films}

During the annealing process, the orientation, crystallinity and the thickness of the newly formed lamellae increased. Changes in the structure of the lamellae would have impacts on the mechanical properties of the specimens. From our previous discussion (Ding et al., 2013), during annealing at $135^{\circ} \mathrm{C}$ for different times, a significant decrease of the yield stress and elastic modulus of the annealed films took place during the first $40 \mathrm{~s}$. After the uniform elastic deformation area, the slopes of each curve were significantly different, especially for the films annealed less than $40 \mathrm{~s}$. Thus, our interest was in the effect of annealing temperature on the tensile deformation behavior of the precursor films. Figure 3 shows the typical stress-strain behavior of the original precursor film and the annealed films along MD direction. All samples showed the typical hard elastic stress-strain characteristics of films of a raw-lamellar morphology. For the unannealed film, an initial elastic response at low deformation followed by one strain hardening zone was obtained, and the stress $\left(\sigma_{\mathrm{y}, \mathrm{u}}\right)$ was almost $90 \mathrm{MPa}$ where the transition from elastic response to the strain hardening zone happened.

Obviously, the stresses at the transition point for the annealed samples and the elastic modulus gradually decrease with increasing annealing temperature. Comparing with the stress-strain curve of the unannealed sample which had only two evident stress increase stages (OA and $\mathrm{AD}$ ), all the annealed films showed three significant stress increase stages. For example, the three significant stress increase stages for the film annealed at $140^{\circ} \mathrm{C}$ were $\mathrm{OB}, \mathrm{BC}$ and $\mathrm{CD}$, respectively. The different stress growth areas corresponded to the response

\begin{tabular}{|c|c|c|c|c|}
\hline $\begin{array}{c}\text { Annealing } \\
\text { temperature } \\
{ }^{\circ} \mathrm{C}\end{array}$ & $\begin{array}{c}\text { Melting peak at lower } \\
\text { temperature }\left(\mathrm{Tm}^{\prime}\right) \\
{ }^{\circ} \mathrm{C}\end{array}$ & $\begin{array}{c}\text { Thickness of the newly } \\
\text { formed lamellae } \\
\mu \mathrm{m}\end{array}$ & $\begin{array}{c}\text { Thickness of the original } \\
\text { lamellae } \\
\mu \mathrm{m}\end{array}$ & $\begin{array}{c}\text { Crystallinity } \\
(\mathrm{Xc})\end{array}$ \\
\hline unannealed & - & - & 18.88 & 43.74 \\
80 & 91.1 & 3.57 & 18.62 & 43.90 \\
90 & 103.8 & 3.92 & 18.41 & 44.09 \\
100 & 111.1 & 4.61 & 18.66 & 46.09 \\
110 & 112.8 & 4.73 & 19.43 & 50.76 \\
120 & 125.6 & 5.81 & 18.96 & 51.44 \\
130 & 135.2 & 6.91 & 18.67 & 51.72 \\
\hline 140 & 147.2 & 8.65 & 18.92 & \\
\hline
\end{tabular}

Table 1. The crystallization properties of the precursor film and annealed films 
of the different structural units. Thus the formation of the new lamellar structures and the changes of $\mathrm{f}_{\mathrm{c}}$ in the annealing process were the reasons for the variation of the stress-strain curves of annealed samples, as described below.

The amorphous phase and the tie chains in the precursor film bear the main load during the elastic deformation process. After the majority of tie chains become incorporated in the new crystallites during annealing, the amorphous moiety of the sample appeared to be depleted. So, compared to the unannealed film, the $\sigma_{\mathrm{y}}$ and elastic modulus of the annealed films decreased and the decreasing of the $\sigma_{\mathrm{y}}$ became more obvious with the increase of the annealing temperature. Compared with the strain-stress curve of the unannealed precursor film, the strain-stress curves of the annealed films immediately switched into the region with a higher slope (BC). The significant difference for the precursor films annealed at different temperatures was caused by the deformation mode of the lamellar structure in the stretching process. A large number of perfect and thick newly formed lamellae could better toughen the original lamellae and fully protect the original lamellae from separation during stretching. In addition, the increasing number and the thickness of the newly formed lamellae mean the reduction of the amorphous content. The decrease of amorphous content would weaken the mechanical strength of the amorphous regions which was also beneficial to the separation of lamellae and the formation of micropores. The improvement of $f_{c}$ resulting from recrystallization could promote the deformation mode of lamellae to transform from twisting, bending, and slippage into separation which was beneficial for the pore formation during stretching.

\subsection{Effect of Annealing on the Performance of the Microporous Membranes}

After annealing at different temperatures for $30 \mathrm{~min}$, the precursor films were stretched at $25^{\circ} \mathrm{C}$ and $120^{\circ} \mathrm{C}$ to create and enlarge pores, respectively. Then the microporous membranes were obtained by heat setting at clamping state at $120^{\circ} \mathrm{C}$ for 20 min after the hot stretching. Figure 4 shows the photo of microporous membranes made from the precursor films which had experienced different annealing temperatures. Due to the
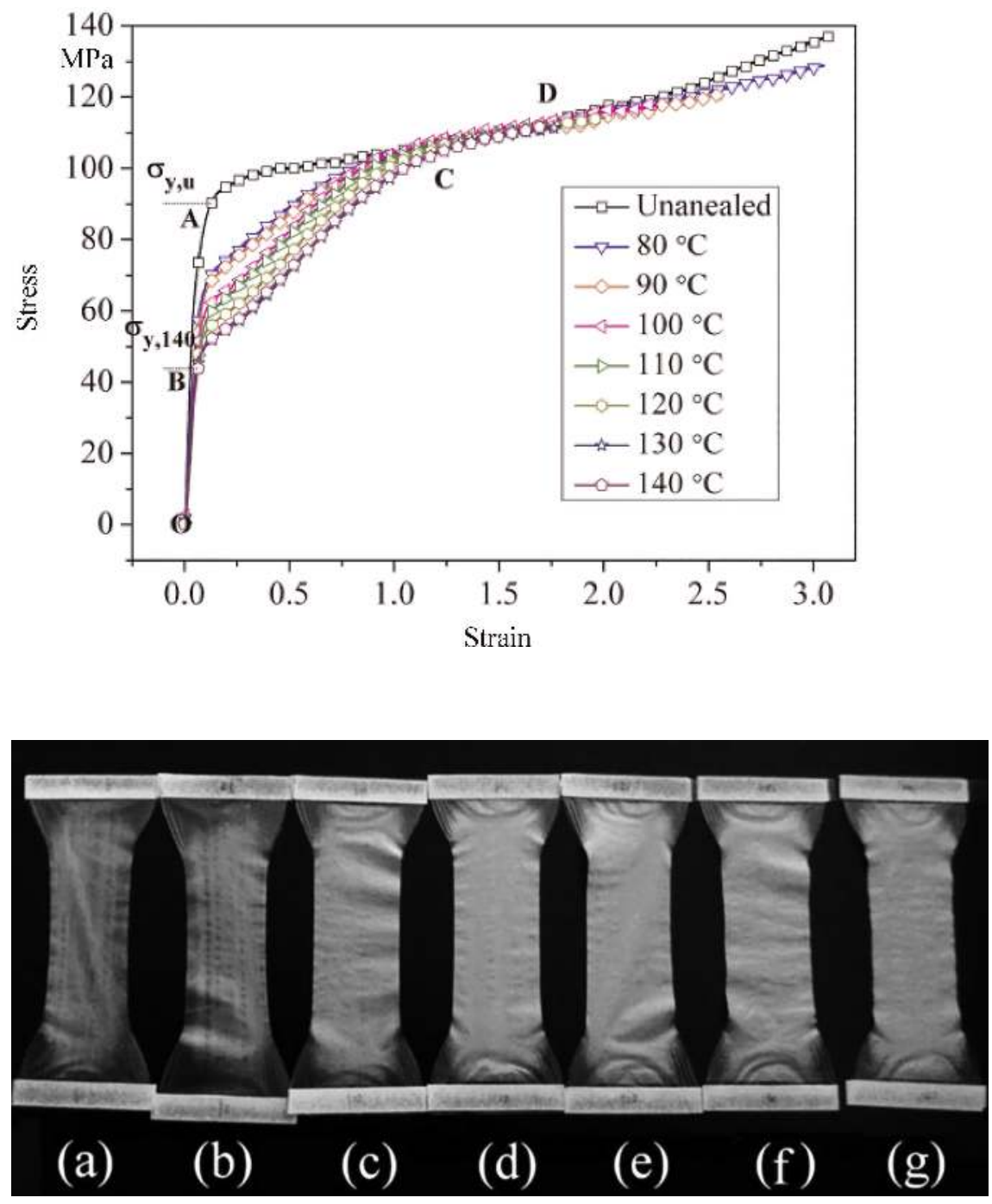

Fig. 3. Stress-strain curves of unannealed film and precursor films annealed at different annealing temperatures for $30 \mathrm{~min}$ 
scattering of natural light in the microporous structure of the membrane, the transparency of the samples can qualitatively describe the number of pores and porosity. The greater the number of micropores in the membranes the whiter it would be and, as a consequence, the larger the porosity and permeability of the microporous membranes. The microporous membranes prepared from precursor films annealed at low temperatures were translucent. With the increase of annealing temperature of the precursor films, the microporous membranes became more and more white, and the degree of necking of the samples reduced markedly. When the annealing temperature of the precursor films was higher than $110^{\circ} \mathrm{C}$, microporous membranes became completely opaque.

In order to detect the effect of annealing temperature on the pore structure of the microporous membranes, SEM was used to observe the surface morphology of each specimen, as shown in Fig. 5. The number of pores on the surface of the microporous membranes increased with increasing annealing temperature. Meanwhile, the pore size increased and the distribution of pore size narrowed down. The porosity of the microporous membranes, shown in Fig. 6, corresponds to the results of Figs. 4 and 5. The porosity of the microporous membrane increased with increasing annealing temperatures of the precursor films. When the annealing temperature was higher than $110^{\circ} \mathrm{C}$ for the precursor film, the porosity of the resultant membranes exceeded $30 \%$. When the annealing temperature varied from $110^{\circ} \mathrm{C}$ to $140^{\circ} \mathrm{C}$, the growth rates of the porosity and pore size of the obtained membranes were slow down with the increasing annealing temperature. In addition, the uniformity of the micropores had a slight enhancement when the annealing temperature increased within the region of $110^{\circ} \mathrm{C}$ to $140^{\circ} \mathrm{C}$.

Based on the discussion above, the micropores membrane obtained by the precursor film being annealed from $110^{\circ} \mathrm{C}$ to $140^{\circ} \mathrm{C}$ possessed superior performance. The improvement of the pore structure was the result of preventing a large degree of twisting, bending, and slippage of lamellae during stretching. It meant that the effective transformation of the lamellar deformation mode occurred at $110^{\circ} \mathrm{C}$. Meanwhile, the microporous membrane obtained by the precursor film being annealed at $140{ }^{\circ} \mathrm{C}$ possessed the most perfect micropores struc- ture. This is why many researchers (Tabatabaei et al., 2008; 2009; Cai et al., 2015) choose $140^{\circ} \mathrm{C}$ as their annealing temperature.

\subsection{Discussion}

The results in this study improved the "core-shell sandwich" structure model that we have previously described (Ding et al., 2013). As shown in Fig. 7, the unannealed precursor film is composed of stacked lamellaes and amorphous regions. During annealing, the molecular chains (including tie chains, tail chains, and loop chains) in the interface between the amorphous regions and the lamellae were the most likely to crystallize. The newly formed lamellae were attached on both sides of the original lamellae to create a "core-shell sandwich" structure. When the annealing temperature increased, more chains in the amorphous regions folded into the crystal lattice, which

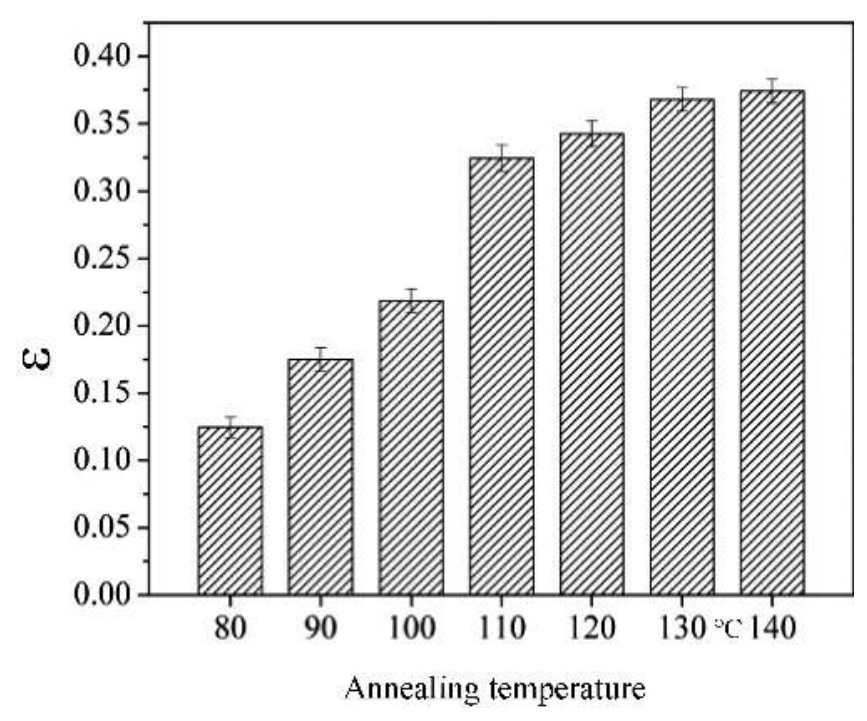

Fig. 6. The porosity ( $\varepsilon$ ) of the microporous membranes made from annealed films with different annealing temperatures
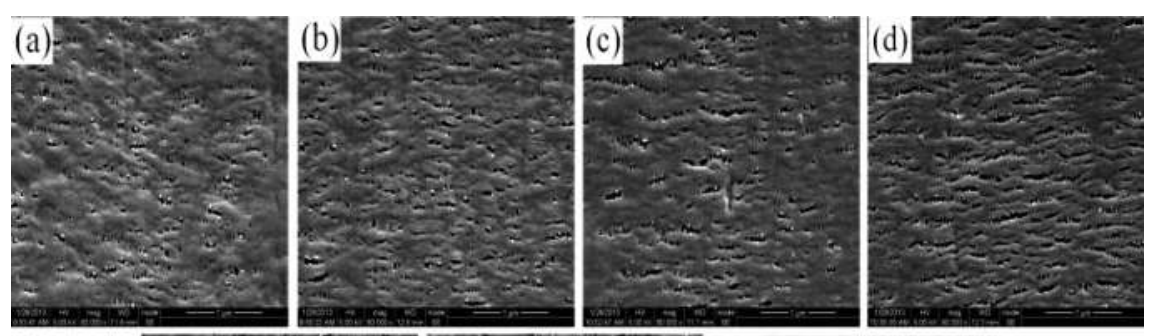
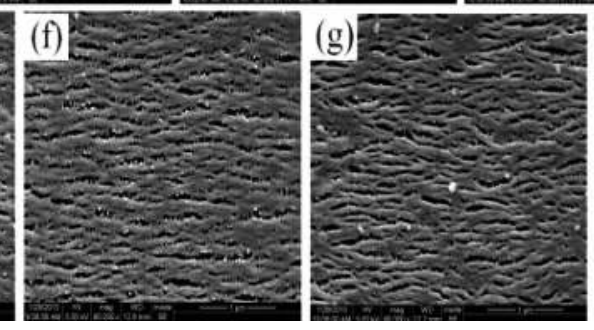

Fig. 5. SEM images of microporous membranes made from annealing films with different annealing temperatures (a) $80^{\circ} \mathrm{C}, \quad(b)$ $90^{\circ} \mathrm{C}$, (c) $100^{\circ} \mathrm{C}$, (d) $110^{\circ} \mathrm{C}$, (e) $120^{\circ} \mathrm{C},(f)$ $130^{\circ} \mathrm{C},(\mathrm{g}) 140^{\circ} \mathrm{C}$ for 30 min annealing time 


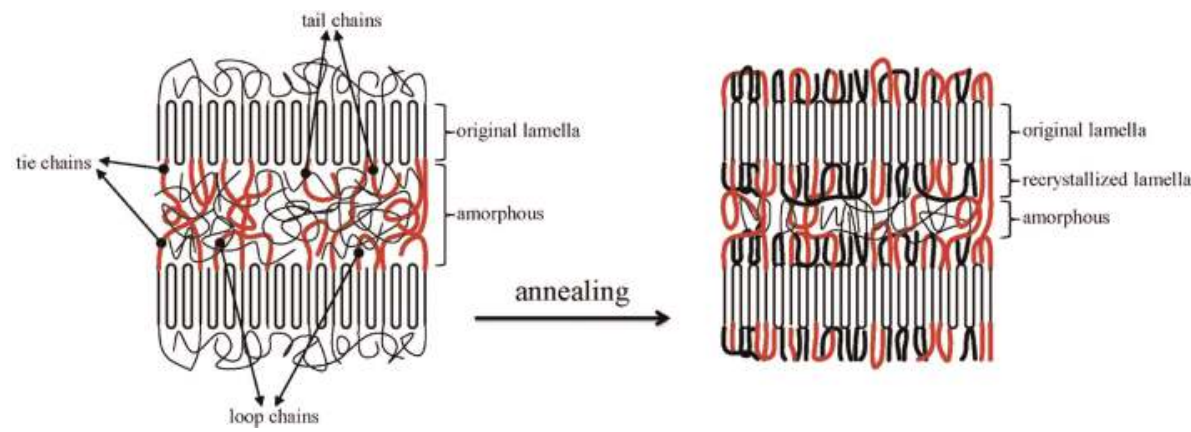

Fig. 7. Sketch of the structure of lamellae developing during annealing induced higher content and thickening of newly recrystallized lamella. The newly recrystallized lamella became more perfect with the increase of the annealing temperature, especially in the temperature ranging from $110^{\circ} \mathrm{C}$ to $140^{\circ} \mathrm{C}$. It can be concluded that the higher the annealing temperature was, the thicker the newly formed lamellae and the more perfect "core-shell sandwich" would be.

\section{Conclusions}

The precursor film was prepared by film extrusion and then annealed at various temperatures for various times. The growth rate of orientation of the annealed precursor film $\left(f_{c}\right)$ increased with the increase of the annealing temperature, especially for the samples annealed at $130^{\circ} \mathrm{C}$ and $140^{\circ} \mathrm{C}$. The thickness of original lamellae remained unchanged during annealing, while the thickness of the newly formed lamellae attached on both sides of the original lamellae, increased with increasing annealing temperature. When the annealing temperature was higher than $110^{\circ} \mathrm{C}$, the newly crystallized lamellae prevented a large degree of twisting, bending, and slippage, the lamellar structure mainly separated along the MD direction. Then, relatively perfect slitlike micropores formed between the separated lamellar structures, which could be proved by the increase of the number of pore structures, the pore size, and the porosity of the microporous membranes with the increasing initial annealing temperatures, especially from $110^{\circ} \mathrm{C}$ to $140^{\circ} \mathrm{C}$. These results showed the effect of annealing temperature on the recrystallization and "core-shell sandwich" structure model, which could explain the microstructural changes of the precursor film during annealing and the pores formation in the samples under stretching.

\section{References}

Arora, P., Zhang, Z. M., "Battery Separators", Chem. Rev., 104, 4419-4462 (2004), DOI:10.1021/cr020738u

Bierenbaum, H. S., Daley, L. R., Zimmerman, D. and Hay, I. L., U.S. Patent 3843761 (1974)

Cai, Q., Xu, R. J., Wu, S. Q., Chen, C. B., Mo, H. B., Lei, C. H., $\mathrm{Li}, \mathrm{L}$. B. and $\mathrm{Li}, \mathrm{Z}$. H., "Influence of Annealing Temperature on the Lamellar and Connecting Bridge Structure of Stretched Polypropylene Microporous Membrane", Polym. Int., 64, 446-452 (2015), DOI:10.1002/pi.4828

Cheng, X. Q., Wang, Z. X., Jiang, X., Li, T. X., Lau, C. H., Guo, Z. H., Ma, J. and Shao, L., "Towards Sustainable Ultrafast Molecular-Separation Membranes: From Conventional Polymer to Emerging
Materials", Prog. Mater. Sci., 92, 258-283 (2018), DOI:10.1016/j.pmatsci.2017.10.006

Clark, E. J., Hoffman, J. D., "Regime III Crystallization in Polypropylene", Macromolecules, 17, 878-885 (1984), DOI: $10.1021 / \mathrm{ma} 00134 \mathrm{a} 058$

Ding Z. T., Bao, R. Y., Zhao, B., Yan, J., Liu, Z. Y. and Yang, M. B., "Effects of Annealing on Structure and Deformation Mechanism of Isotactic Ppolypropylene Film with Row-Nucleated Lamellar Structure", J. Appl. Polym. Sci., 130, 1659-1666 (2013), DOI:10.1002/app.39351

Ding, Z. T., Liu, Z. Y., Feng, J. M., Yang, W. and Yang, M. B., "Effect of the Content of High Molecular Weight Component on PP Microporous Membranes Obtained by Melt-Extrusion-Stretching Method", Acta Polymerica Sinica, 462-468 (2012), DOI:10.3724/SP.J.1105.2012.11324

Himma, N. F., Anisah, S., Prasetya, N. and Wenten I. G., "Advances in Preparation, Modification, and Application of Polypropylene Membrane", J. Polym. Eng., 36, 329-362 (2016),

DOI:10.1515/polyeng-2015-0112

Lee, S. Y., Park, S. Y. and Song, H. S., "Lamellar Crystalline Structure of Hard Elastic HDPE Films and its Influence on Microporous Membrane Formation", Polymer, 47, 3540-3547 (2006), DOI:10.1016/j.polymer.2006.03.070

Li, Y. J., Pu, H. T. and Wei, Y. L., "Polypropylene/Polyethylene Multilayer Separators with Enhanced Thermal Stability for Lithium-Ion Battery via Multilayer Coextrusion", Electrochim. Acta, 264, 140 - 149 (2018), DOI:10.1016/j.electacta.2018.01.114

Lin, Y. F., Li, X. Y., Meng, L. P., Chen, X. W., Lv, F., Zhang, Q. L., Zhang, R. and Li, L. B., "Structural Evolution of Hard-Elastic Isotactic Polypropylene Film during Uniaxial Tensile Deformation: The Effect of Temperature", Macromolecules, 51, 2690-2705 (2018), DOI:10.1021/acs.macromol.8b00255

Liu, J., Ding, Z. T., Liu, Z. Y., Feng, J. M., Yang, W. and Yang, M. B., "Effect of Roller Rates and Temperatures on the Structure of HDPE Stretched Microporous Membranes and Lamellae", Acta Polymerica Sinica, 1278-1283 (2011), DOI:10.3724/SP.J.1105.2011.10328

Rosova, E. Y., Karpov, E. A., Lavrentiev, V. K. and Elyashevich, G. K., "The Effect of Annealing on Structural Rearrangements and Mechanical Properties of Hard Elastic Polyethylene", PPS-12 Annual Meeting, Sorrento, Italy, 297 (1996)

Sadeghi, F., Ajji, A. and Carreau, P. J., "Analysis of Microporous Membranes Obtained from Polypropylene Films by Stretching", J. Membr. Sci., 292, 62-71 (2007), DOI:10.1016/j.memsci.2007.01.023

Saffar, A., Ajji, A., Carreau, P. J. and Kamal, M. R., "The Impact of New Crystalline Lamellae Formation during Annealing on the Properties of Polypropylene Based Films and Membranes", Polymer, 55, 3156-3167 (2014), DOI:10.1016/j.polymer.2014.05.017

Tabatabaei, S. H., Carreau, P. J. and Ajji, A., "Microporous Membranes Obtained from Polypropylene Blend Films by Stretching", J. Membr. Sci., 325, 772-782 (2008), DOI:10.1016/j.memsci.2008.09.001

Tabatabaei, S. H., Carreau, P. J. and Ajji, A., "Effect of Processing on the Crystalline Orientation, Morphology, and Mechanical Properties of Polypropylene Cast Films and Microporous Membrane Formation", Polymer, 50, 4228-4240 (2009),

DOI:10.1016/j.polymer.2009.06.071 
Tabatabaei, S. H., Carreau, P. J. and Ajji, A., "Microporous Membranes Obtained from PP/HDPE Multilayer Films by Stretching", J. Membr. Sci., 345, 148-159 (2009),

DOI:10.1016/j.memsci.2009.08.038

Valles-Lluch, A., Contat-Rodrigo, L. and Ribes-Greus, A., "Differential Scanning Calorimetry Studies on High-and Low-Density Annealed and Irradiated Polyethylenes: Influence of Aging", J. Appl. Polym. Sci., 89, 3260-3271 (2003), DOI:10.1002/app.12479

Wang, S., Saffar, A., Ajji, A., Wu, H. and Guo, S. Y., "Fabrication of Microporous Membranes from Melt Extruded Polypropylene Precursor Films via Stretching: Effect of Annealing", Chin. J. Polym. Sci., 33, 1028 - 1037 (2015), DOI:10.1007/s10118-015-1643-x

Włochowicz, A., Eder, M., "Distribution of Lamella Thicknesses in Isothermally Crystallized Polypropylene and Polyethylene by Differential Scanning Calorimetry", Polymer, 25, 1268-1270 (1984), DOI:10.1016/0032-3861(84)90374-4

Xiong, B. J., Chen, R., Zeng, F. X. Y., Kang, J. and Men, Y. F., "Thermal Shrinkage and Microscopic Shutdown Mechanism of Polypropylene Separator for Lithium-ion Battery: In-situ Ultra-Small Angle X-Ray Scattering Study", J. Membr. Sci., 545, 213-220 (2018), DOI:10.1016/j.memsci.2017.10.001

Xu, R. Z., Zeng, S., Wang, J. T., Kang, J., Xiang, M. and Yang, F., "Impact of Different Die Draw Ratio on Crystalline and Oriented Properties of Polypropylene Cast Films and Annealed Films", J. Polym. Res., 25, 142 (2018), DOI:10.1007/s10965-018-1534-2

Xu, R. J., Chen, X. D., Xie, J. Y., Cai, Q. and Lei, C. H., "Influence of Melt-Draw Ratio on the Crystalline Structure and Properties of Polypropylene Cast Film and Stretched Microporous Membrane", Ind. Eng. Chem. Res., 54, 2991 - 2999 (2015),

DOI:10.1021/acs.iecr.5b00215

\section{Acknowledgements}

This research was supported by the National Natural Science Foundation of China (Grant No. 51422305, 51721091). The authors wish to acknowledge Dr. Chaoliang Zhang (West China College of Stomatology, Sichuan University) for SEM observations.

Date received: October 17, 2018

Date accepted: May 12, 2019

Bibliography

DOI 10.3139/217.3774

Intern. Polymer Processing

XXXIV (2019) 4; page 467-474

(c) Carl Hanser Verlag GmbH \& Co. KG

ISSN 0930-777X 